the somatic component of the sphincter complex. After the abdomen is closed the anal sphincter is incised vertically a little to one side of the mid-line posteriorly and divided until the gut tube is exposed. The portion of gut tube bearing the tumour is then delivered and the resection carried out. The line of the anastomosis is easily accessible and it is then a straight-forward matter to achieve a really low resection with a technically satisfactory anastomosis. Recovery of sphincter function after resuture of the somatic sphincter is excellent.

An alternative method of achieving a low anastomosis has been described using the transanal approach. ${ }^{10}$ The anorectal stump is dilated sufficiently to admit a specially designed retractor. The tumour is resected through the abdomen. The cut end of the left colon is then drawn down into the pelvis and sutured to the anorectal stump from within the lumen using a specially designed needle. Again the functional results of this operation are very satisfactory.

In summary, then, it is no longer satisfactory always to treat carcinoma of the rectum by either abdominoperineal excision or a standard anterior resection. A clear understanding of the pathological nature of the disease and the fact that further techniques are available to allow a really low anastomosis means that growths of even $6 \mathrm{~cm}$ and upwards should be considered for some sort of restorative procedure, especially if the tumour is of average or below average malignancy.

\footnotetext{
1 Morgan, C. N., Annals of the Royal College of Surgeons of England, 1965, $36,73$.

2 Bennett, R. C., Medical fournal of Australia, 1974, 2, 83

3 Devlin, H. B., Plant, J. A., and Griffin, M., British Medical Fournal, 1971, $3,413$.

4 Quer, E. A., Dahlin, D. C., and Mayo, C. W., Surgery, Gynecology and Obstetrics, 1953, 96, 24

${ }^{5}$ Goligher, J. C., et al., British fournal of Surgery, 1965, 52, 323.

- Goligher, J. C., Graham, N. G., and De Dombal, F. T., British fournal

7 of Surgery, 1970, 57, 109.

8 Kennedy, J."T., et al., British Fournal of Surgery, 1970, 57, 589.

${ }^{8}$ Kennedy, J. T. Mason, A. Y., Proceedings of the Royal Society of Medicine, 1972, 65, 974.

10 Parks. A. G., Proceedings of the Royal Society of Medicine, 1972, 65, 975.
}

\section{Insecticides and Cancer}

In assessing any risk that people exposed to drugs and chemicals in the environment or at their place of work might develop acute or chronic poisoning, it is frequently and rightly emphasized that judgement is required. Experts who are familiar with the practical situation and those who are competent to judge the available evidence (be it of a statistical, biochemical, or pathological nature) must use their professional judgement when offering an opinion on its interpretation.

The Environmental Protection Agency of the U.S.A. has recently recommended a ban on the further production of the insecticides aldrin and dieldrin on the grounds that they present "a significant potential of an unreasonable risk of cancer in the American public." The agency's inquiry was held by a judge on its staff, who rejected the evidence of one expert witness who had served on committees on the safety of insecticides. In fact there is no direct evidence that aldrin and dieldrin cause cancer in man nor, with one exception, in animal experiments. The evidence on which the suggestion of "an unreasonable risk of cancer" is based is the production in mice given diets containing aldrin or dieldrin of tumours in the livers, some of which had metastasized to the lungs. Similar tumours can, however, occur in mice on normal diets and are produced by other compounds including
DDT and phenobarbitone; so it is a matter of opinion how far the production of these liver tumours in mice given aldrin or dieldrin is a reliable index of a hazard to man. It is not a matter of the credibility of witnesses: the facts are not in dispute, it is their interpretation that is a matter of debate. These observations are not new but were available for discussion at the time the British Government's review of the problem of persistent organochlorine pesticides was in preparation. ${ }^{1}$ Much of the work on the effects of dieldrin on mice had been carried out in the laboratories of the manufacturer, whose research workers discussed the significance of their findings on many occasions with the scientists advising the committee. The decision taken then was that the use of dieldrin and aldrin should be phased out-because they were persistent and not because of any toxic hazard they present to man. There is good evidence that this phasing out is in fact happening.

In the absence of any new evidence that aldrin or dieldrin are carcinogenic to animals or man there seems no reason for the authorities in this country to follow the American recommendation. Furthermore, where there is no consensus of opinion on the interpretation of findings in animals studies designed to provide evidence of possible toxic hazards to man, the procedure adopted by the Environmental Protection Agency for reaching a decision is not one we should attempt to imitate.

${ }^{1}$ Department of Education and Science, Further Review of Certain Persistent Organochlorine Pesticides. London, H.M.S.O., 1969.

\section{Calcium, Magnesium, and Diuretics}

Since oral diuretic agents are given to so many patients with hypertension and heart failure for long periods of their lives the toxicology of these drugs is important. Can they cause diabetes mellitus de novo or do they merely exacerbate preexisting disease ? Is diuretic-induced hyperuricaemia merely a biochemical epiphenomenon or itself a cause of renal impairment? If diuretics do lower serum potassium concentrations, do they also cause depletion of whole-body potassium stores, and if so, does this matter? As if these questions were not enough to tax most doctors, another facet of diuretic therapy has recently emerged and deserves attention: the effect of diuretics on calcium and magnesium homoeostasis.

Benzothiadiazine (or thiazide) diuretics have two effects on calcium metabolism which are not produced by other diuretic agents. When given for the first time, diuretics such as frusemide, ${ }^{1}$ ethacrynic acid, ${ }^{2}$ and aldosterone antagonists ${ }^{3}$ will enhance calcium excretion by the kidney along with sodium elimination. Not so the thiazides, which affect calcium eliminatlon very little in those circumstances ${ }^{4}$; and indeed long-term thiazide administration results in a persistent reduction in renal calcium elimination ${ }^{5}$ which may lead to hypercalcaemia. The mechanism of this renal effect of the thiazides is not clear. It has been attributed to the ability of thiazide diuretics to deplete extracellular volume, but this appears unlikely since infusion of a thiazide into one renal artery results in unilateral hypocalciuria. ${ }^{6}$ Stimulation of parathyroid hormone secretion does not appear to be a likely explanation, since the effect is seen in animals after thyro-parathyroidectomy, ${ }^{7}$ and, more- 